\title{
Optimization of Train Trip Package Operation Scheme
}

\author{
Lu Tong, Lei Nie, Zhenhuan He, and Huiling Fu \\ School of Traffic and Transportation, Beijing Jiaotong University, Beijing 100044, China \\ Correspondence should be addressed to Lu Tong; tonglu_bjjt@163.com
}

Received 25 September 2014; Accepted 12 January 2015

Academic Editor: Orwa J. Houshia

Copyright (C) $2015 \mathrm{Lu}$ Tong et al. This is an open access article distributed under the Creative Commons Attribution License, which permits unrestricted use, distribution, and reproduction in any medium, provided the original work is properly cited.

\begin{abstract}
Train trip package transportation is an advanced form of railway freight transportation, realized by a specialized train which has fixed stations, fixed time, and fixed path. Train trip package transportation has lots of advantages, such as large volume, long distance, high speed, simple forms of organization, and high margin, so it has become the main way of railway freight transportation. This paper firstly analyzes the related factors of train trip package transportation from its organizational forms and characteristics. Then an optimization model for train trip package transportation is established to provide optimum operation schemes. The proposed model is solved by the genetic algorithm. At last, the paper tests the model on the basis of the data of 8 regions. The results show that the proposed method is feasible for solving operation scheme issues of train trip package.
\end{abstract}

\section{Introduction}

Railway transportation is one of the main types of modern transportation. Railway transportation has the features of fast speed, low costs, environmental friendship, high reliability, accuracy, and continuity. Before the completion of highspeed railway network, railway transportation in China heavily focused on passenger transport. For this reason, railway freight transportation was always restricted by the problem of insufficient capacity. With the operation of motor trains and high-speed railway in recent years, a large number of railway capacities have been released and applied to freight transportation. As the main form of railway freight transportation, train trip package transportation is becoming increasingly important. Meanwhile, it is also becoming more complex due to increased railway transport resources.

Train trip package transportation provides luggage and parcel transportation, fast freight, and joint logistics services. Train trip package transportation is based on the existing railway network and uses passenger baggage cars, train trip packages, and mail train lines as the carrier. With the rapid development of social economy and the growing requirement of perfecting transportation service, railway package transportation has been improving its level of service and has become the main body of rapid railway freight transportation.
There are two main types of railway freight transportation: one is the package marshaled in the passenger train; the other is transport by a specialized train which consists of a certain number of baggage compartments and has fixed stations, fixed time, and fixed path. The second type is normally called the train trip package transportation. In the near future, train trip package transportation will become the main form of package transportation. Therefore, a reasonable train trip package operation scheme can help to improve the level of train trip package organization and the quality of service.

Most of the current researches have focused on the passenger train operation scheme, but few focused on train trip package operation scheme [1-10]. Crainic [11] summarized the transportation services network issues. Barnhart et al. [12] regarded railway marshaling issues as network design problems, where the network nodes represented marshaling yard, and the arc segments represented marshaling train. Chang et al. [13] used fuzzy mathematical programming to study Taiwan high-speed railway train operation plan. Crainic and Rousseau [14] used the heuristic algorithm based on decomposition method and the column generation method to solve railway freight service network design problem with no capacity limits. Bussieck et al. [15] discussed the operation plan optimization problem with periodic timetable. Yu et al. [16] proposed a transit operation for passengers 

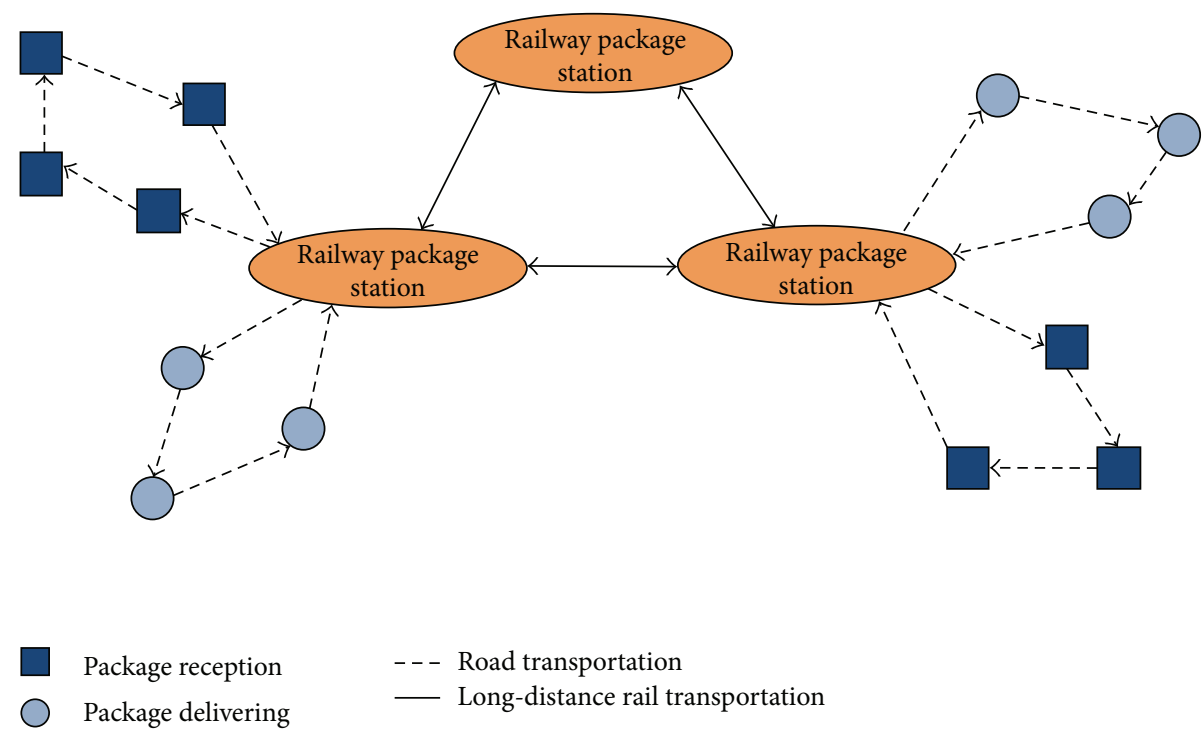

FIgURE 1: The whole process of package transportation.

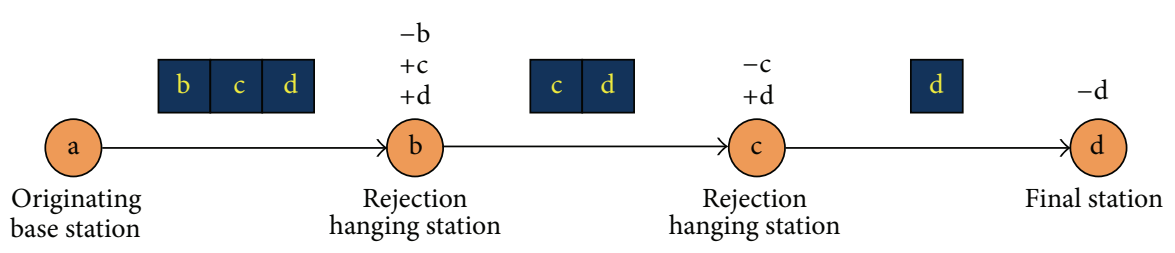

FIGURE 2: The operation process of grouped trains.

transportaion, which considered passenger attraction from canidate nodes to destination nodes. It is a novelty method to the best of our knowledge. Newton et al. [17] established a path-based model without considering the associated fixed costs of trains but adding capacity constraints to restrict the number of trains which could be marshaled and the freight amount which could be handled. Due to some similar features of "passenger train" and train trip package, the train trip package operation scheme optimization can refer to existing research of passenger train operation scheme.

In this paper, the existing research results and experiences of passenger train operation scheme are studied. Then the related factors of train trip package operation scheme are analyzed from its organizational characteristics. A mathematical model is developed to optimize the train trip package operation scheme for practical situation. At the end, the proposed model is verified through an example, and some conclusions are obtained from the experiment.

\section{Problem Description}

The whole process of package transportation can be divided into three operational phases: reception and delivery in the stations of two ends and long-distance rail transportation between the stations. The whole process of package transportation and the relationship among the operational phases are shown in Figure 1. In this paper, we only consider longdistance railway transport between stations and develop a reasonable operation scheme.

In train trip package transportation, the train marshaling is composed of package trains with the same final station (single set of trains) or package trains whose final stations are in the same running path (grouped trains). The operation process of grouped trains is shown in Figure 2. Grouped trains start from the originating base station and will gradually turn into a single set of trains after rejection and hanging for once or several times along the way. When grouped trains reach the rejection and hanging stations before the final station, they are required for rejection and hanging operations.

\section{Model}

3.1. Model Assumption. Through the analysis of organizational characteristics of train trip package transportation, we first make the following assumptions before establishing the optimization model of train trip package operation scheme.

(1) The path of train trip package has been already predetermined.

(2) The transport capacity of train trip package is not restricted and the ability to receive and send trains of 


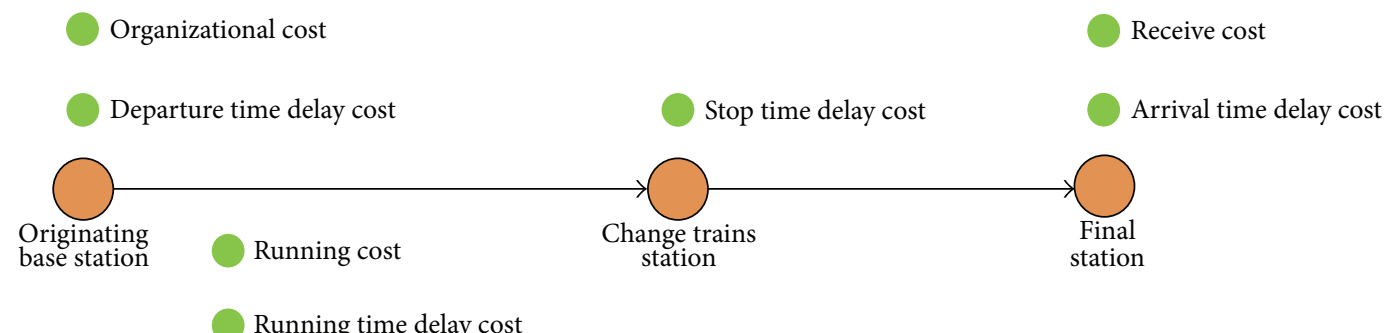

FIgURE 3: Expenses in the service process of train trip package.

each package station can satisfy any traffic intensity; each path can satisfy any traffic intensity.

(3) Operation details and operation process inside stations are not considered, because the operation of train trip package only reflects the influence on the operation scheme in some important links, such as loading costs, rejection, and hanging operations costs.

(4) The operation of train trip package depends on the traffic situation and does not consider the constraints of facing operation.

\subsection{Parameter Setting}

$C$ represents the cost per vehicle kilometer in train trip package transportation;

$C_{0}$ is the rejection and hanging costs for a train;

$P_{i j}$ is the train flow leading from region $i$ to region $j$;

$A_{r s}$ represents the collection of links that are passed by train trip package between regions $r$ and $s$;

$L_{r s}$ is the transport distance between regions $r$ and $s$; $x_{i j}^{r s}$ represents the train flow between regions $r$ and $s$ which are in the path from region $i$ to region $j$;

$\alpha_{i j}^{r s}$ is $0-1$ variable, if the railway freight flows between regions $r$ and $s$ are carried by train trip packages from region $i$ to region $j, \alpha_{i j}^{r s}=1$; otherwise, $\alpha_{i j}^{r s}=0$;

$\mu_{0}$ represents the number of trains that can be marshaled in a set of grouped trains;

$n_{r s}$ is the number of train trip packages between regions $r$ and $s$;

$M$ represents infinity.

3.3. Modeling. All the expenses in the service process of train trip package are shown in Figure 3.

3.3.1. Loading Cost. Train trip package transport is a kind of contractual transport and the contractors are obligated to organize shipments. In principle, the contractors of train trip package need to load and unload packages by themselves. Therefore, the cost of train trip package in loading place is considered as a constant which is denoted by the average loading cost.
3.3.2. Rejection and Hanging Cost. A single set of trains do not need rejection and hanging operations in the middle station. Grouped trains need rejection and hanging operations in the operation stations along the way but do not need loading, unloading, and modifying marshaling operations. Therefore, the rejection and hanging cost only existed in the grouped trains and can be considered as a fixed value.

In the model established in this paper, the total cost of train trip package transportation consists of two parts: one is in-transit cost such as locomotive traction cost and line usage cost which are decided by the cost per vehicle kilometer; the other is the rejection and hanging cost which is decided by the rejection and hanging costs for a train. Because the loading cost of train trip package can be considered as fixed, loading cost is not reflected in the model.

The optimization model of train trip package operation is

$$
\begin{aligned}
& \text { Min } \quad Z=\sum_{i j} \sum_{r s} \sum_{k \in A_{r s} \cap A_{i j}} C L_{k} x_{i j}^{r s} \\
& \quad+C_{0} \sum_{i j}\left(\sum_{r s} x_{i j}^{r s}-x_{i j}^{i j}\right), \\
& \text { s.t. } \quad \sum_{i j} x_{i j}^{r s}=P_{r s} \quad \forall r, s \in S, \\
& \quad x_{i j}^{r s}-\alpha_{i j}^{r s} \cdot M \leq 0 \quad \forall r, s, i, j \in S, \\
& \quad \sum_{r s} x_{i j}^{r s} \leq n_{i j} \mu_{0} \quad \forall i, j \in S, \\
& \quad x_{i j}^{r s} \geq 0 \quad \forall r, s, i, j \in S, \\
& n_{r s} \geq 0, \quad n_{r s} \text { is integer. }
\end{aligned}
$$

The purpose of objective function (1) is to minimize the total operation cost of all train trip packages.

Constraint (2) is the flow conservation constraint, ensuring that train trip package operation scheme meets the transport demand between each OD pair.

Constraint (3) ensures that the railway freight flows carried by train trip packages are assigned to feasible path.

Constraint (4) ensures that the number of train flows in each service interval does not exceed the carrying capacity the train service can provide.

Constraints (5) and (6) are nonnegative constraints of the decision variables and constraint (6) requires the number of train trip packages to be integers. 


\begin{tabular}{l|c|c|c|c|}
\hline Chromosome & 1 & 3 & 5 & 8 \\
\hline
\end{tabular}

3.4. Genetic Algorithm. Because the formulation of train trip package operation scheme is a linear discrete optimization problem, the traditional method is difficult to get the optimal solution to the problem. Many literatures suggested that heuristic algorithm was often the first choice to solve this kind of complicated transportation optimization problems [18-21]. Among heuristic algorithms, genetic algorithm (GA) is a probabilistic search algorithm for global optimization. The genetic algorithm is formed by simulating biological genetic and evolutionary processes in the natural world. Genetic algorithm has good global search capability and fast calculation speed. It can quickly find an optimal solution from the entire solution space and will seldom fall into the local optimal solution. Currently, genetic algorithm has achieved good application in the path optimization, site selection, and other aspects which has been applied to solve lots of complicated problems [22-25]. Therefore, the genetic algorithm is used in this paper to solve the problem.

Step 1 (coding). The decimal coding is employed to generate an array of numbers, namely, a chromosome. Each chromosome represents an operation sequence of train trip package (Figure 4). A gene in a chromosome represents a station that train trip packages pass by; for example, $1-3-5-8$ represents that train trip packages start from station 1 and finally get to station 8 , passing by station 3 and station 5 .

Step 2 (generating initial populations). According to OD flows between package stations, we successively select each OD pair and find a path between stations to produce a feasible chromosome. Repeat the process until feasible chromosomes between each OD pair have been produced.

Step 3 (calculation of fitness value). Clearly, some chromosomes may not satisfy all of the constraints in the model. Therefore, it is necessary to construct the fitness function. Adaptation function indicates the superiority of chromosomes. For the minimum value problem in this paper, the fitness function is

$$
\begin{aligned}
& F\left(x^{\prime}\right) \\
& \quad=N-\sum_{i j} \sum_{r s} \sum_{k \in A_{r s} \cap A_{i j}} C L_{k} x_{i j}^{r s}-C_{0} \sum_{i j}\left(\sum_{r s} x_{i j}^{r s}-x_{i j}^{i j}\right) .
\end{aligned}
$$

In the formula, the value of $N$ will be determined according to the size of the problem, to ensure $F\left(x^{\prime}\right) \geq 0$.

Step 4 (selection and crossover (Figure 5)). Roulette method is used as a selection mechanism. In the roulette method,

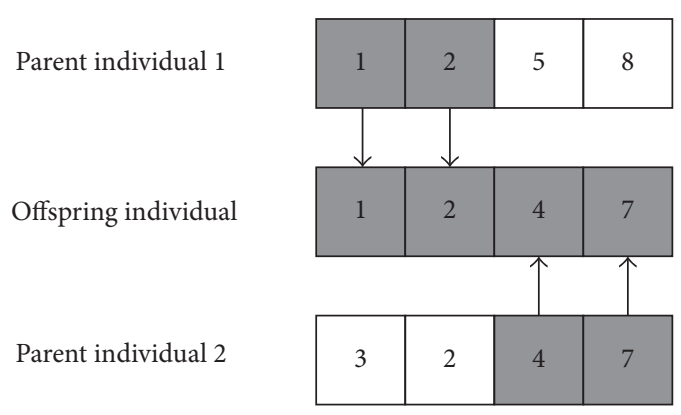

FIGURE 5: Crossover operator of genetic algorithm.

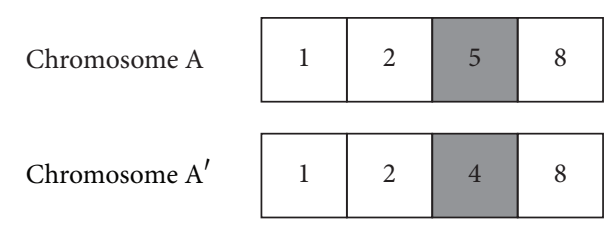

FIGURE 6: Mutation operator of genetic algorithm.

chromosomes will be selected for reproducing a new generation with certain probability. The selection probability of a chromosome is related to its fitness. Generally, the higher the fitness value, the bigger the selection probability. Meanwhile, the elite strategy is also implemented, which means the chromosome with the maximum fitness value in each generation of populations will be copied to the next generation. The optimal policy makes the next generation not worse than the parent generation.

Crossover introduces random changes to the selected chromosomes by crossing two parent individuals to produce offspring individuals with a user-specified probability $p_{c}$ called crossover rate. In this paper, the single-point crossover is implemented.

Step 5 (mutation). Mutation introduces random changes to the chromosomes by altering the value of a gene with a userspecified probability $p_{m}$ called mutation rate (Figure 6).

Step 6 (stopping criterion). To compare the computation efficiency of different algorithms, different stopping times are set as the stopping criteria. When getting to the predetermined stopping time, the algorithm ends.

\section{Numerical Test}

Based on "three vertical and four horizontal" train transportation physical network of China, eight package stations are chosen to build a spatial network graph of package transportation regions (as shown in Figure 7); then design a service network of train trip package. The purpose is to determine the organization form, the running paths, and the operation number of trains. 


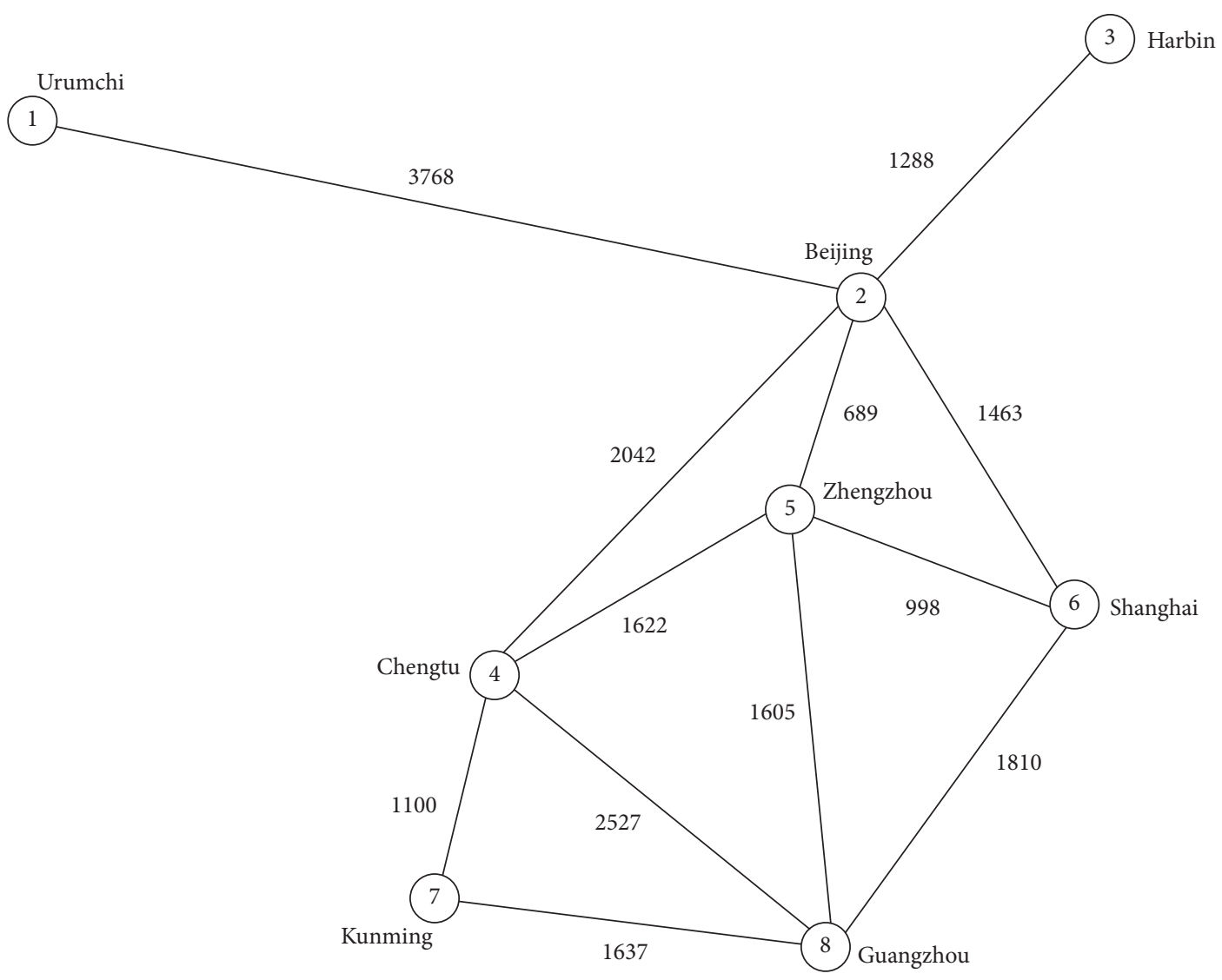

FIGURE 7: Spatial network graph of package transportation regions.

TABLE 1: Space distance of package transportation regions $(\mathrm{km})$.

\begin{tabular}{lcccccccc}
\hline Region & 1 & 2 & 3 & 4 & 5 & 6 & 7 & 8 \\
\hline 1 & - & 3768 & - & - & - & - & - & - \\
2 & & - & 1288 & 2042 & 689 & 1463 & - & - \\
3 & & & - & - & - & - & - & - \\
4 & & & & - & 1622 & - & 1100 & 2527 \\
5 & & & & & - & 998 & - & 1605 \\
6 & & & & & & - & - & 1810 \\
7 & & & & & & & - & 1637 \\
8 & & & & & & & & - \\
\hline
\end{tabular}

\subsection{Data Preparation}

4.1.1. Data of Interregional Distance. As the spatial network graph of package transportation regions shown in Figure 7, the actual length of the links between each node pair can be considered as the distance between center cities of each region. Specific distance data are shown in Table 1.

4.1.2. Data of OD Flows. According to the statistics of China railway transportation, Table 2 shows OD flows by package between 8 package regions, in units of tons per year.

In this paper, assume that the length of the design cycle is one day and the OD flows for each period are constant. It is known that the OD flows in Table 2 are represented in units of tons per year, so a conversion coefficient is introduced here to obtain daily OD flows in units of trains/day.

Since the volume of packages is difficult to accurately grasp in the actual operation, the deadweight constraint of package trains is considered as an alternative. The deadweight capacity of a package train is averagely 15 tons according to our survey and a year is calculated as 365 days. The result of the conversion is shown in Table 3 . Note that the numbers of package trains have to be integer value, so the final conversed values are rounded off.

4.1.3. Cost Data. The average operating cost is set to 90 per vehicle kilometer $(C=90)$ and the rejection and hanging operating costs are set to 1000 per train $\left(C_{0}=1000\right)$.

4.1.4. Other Data. According to the regulation of the number of marshaling train trip packages, $\mu_{0}=20$.

4.2. The Results. Based on the above model parameters, the genetic algorithm is used to calculate model through $\mathrm{C}++$ programming. The crossover probability of GA is set as 0.8 and the mutation probability is set as 0.05 . The maximum evolution generation of GA is set as 100 . The specific results are shown in Table 4. 
TABLE 2: OD flows by package among 8 package regions (tons/year).

\begin{tabular}{lcccccccc}
\hline Region & 1 & 2 & 3 & 4 & 5 & 6 & 7 & 8 \\
\hline 1 & - & 139790 & 8284 & 34410 & 20431 & 80648 & 10753 & 44088 \\
2 & 50294 & - & 62909 & 136105 & 57034 & 140123 & 67275 \\
3 & 7710 & 96678 & - & - & - & 32028 & - & 108884 \\
4 & 88962 & 172889 & - & - & 120854 & 119176 & 186317 \\
5 & 13255 & 46392 & - & 26510 & - & 64381 & - & 100712 \\
6 & 44764 & 135649 & 42155 & 121667 & 104032 & - & 59998 \\
7 & 20523 & 79930 & - & 106933 & - & 74529 & - & 709145 \\
8 & 31014 & 180416 & 39662 & 96321 & 79025 & 188766 & 65606 & - \\
\hline
\end{tabular}

TABLE 3: Daily OD train flows among 8 package regions (train/day).

\begin{tabular}{lcccccccc}
\hline Region & 1 & 2 & 3 & 4 & 5 & 6 & 7 & 8 \\
\hline 1 & - & 26 & 2 & 6 & 4 & 15 & 2 & 8 \\
2 & 9 & - & 11 & 25 & 10 & 26 & 12 & 20 \\
3 & 1 & 18 & - & - & - & 6 & - & 3 \\
4 & 16 & 32 & - & - & 22 & 22 & 34 & 18 \\
5 & 2 & 8 & - & 5 & - & 12 & - & 6 \\
6 & 8 & 25 & 8 & 22 & 19 & - & 11 & 20 \\
7 & 4 & 15 & - & 20 & - & 14 & - & 13 \\
8 & 6 & 33 & 7 & 18 & 14 & 34 & 12 & - \\
\hline
\end{tabular}

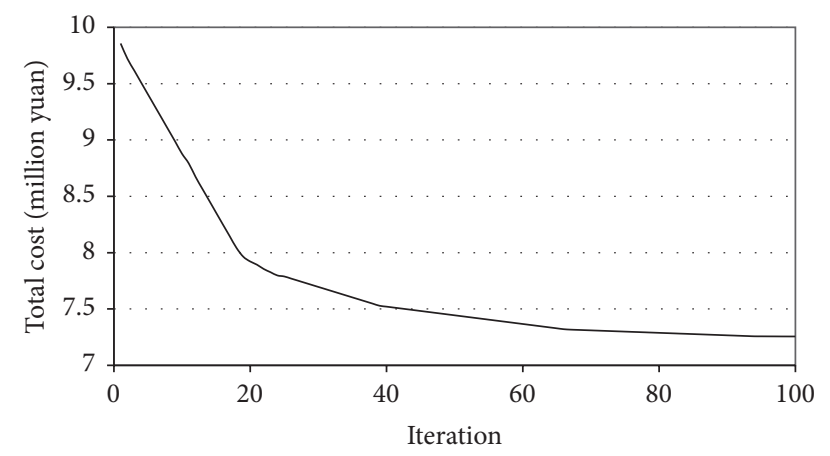

FIGURE 8: Result of each calculation.

As shown in Table 4, parts of OD flows between stations are transported directly from the start station to the final station, without any transit operations. The other parts of OD flows are required to stop at middle stations for rejection and hanging.

4.3. Test Results Discussion. Figure 8 depicts the convergence of the calculation. The results of computational tests show that the algorithm of this paper can achieve convergence within 100 generations, indicating a good convergence and a good adaptability to solve the proposed model.

It is known that the initial operation scheme consists of 48 single sets of trains. All OD flows are transported directly from the start station to the final station, without any operation in transit. Target cost of initial operation scheme is 9.8574 million yuan.

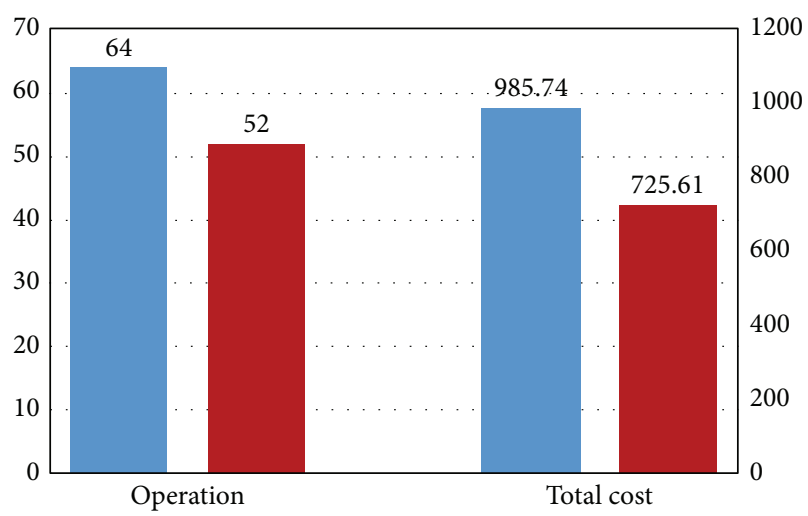

Initial operation scheme

Optimized scheme

FIGURE 9: Comparison of the results.

After optimization, the sample train transport service network consists of 26 kinds of train trip package transport services. In the optimized operation scheme, there are 52 operations within a day, including 45 operations of single set of trains and 7 of grouped trains. Compared with the initial scheme, the optimized scheme reduces the operation number of single set of trains in long distance and yet increases the operation number of both single set of trains and group trains in short/middle distance, thus reducing the total cost of train transportation. The total cost of the optimized scheme is 7.2561 million yuan, reduced by $26.4 \%$ compared with the initial one.

To evaluate the performance of the proposed scheme, the results of initial operation scheme and optimized scheme can be showed in Figure 9. It can be found that the optimized scheme can greatly reduce the total cost. Thus, the proposed optimized scheme is an effective method for train trip package optimization.

\section{Conclusions}

This paper focuses on how to arrange the train trip package operation scheme to lower the transportation cost. An optimization model is established based on the analysis of 
TABLE 4: Calculation results train trip package operation scheme.

\begin{tabular}{|c|c|c|c|c|c|c|}
\hline Number & Originating station & Final station & Running path & The number of train flows & Operation number & Organizational form \\
\hline 1 & 1 & 2 & $1 \rightarrow 2$ & 27 & 2 & Single \\
\hline 2 & 1 & 4 & $1 \rightarrow 4$ & 12 & 1 & Single \\
\hline 3 & 1 & 5 & $1 \rightarrow 5$ & 8 & 1 & Single \\
\hline 4 & 2 & 1 & $2 \rightarrow 1$ & 11 & 1 & Single \\
\hline 5 & 2 & 3 & $2 \rightarrow 3$ & 28 & 2 & Single \\
\hline 6 & 2 & 4 & $2 \rightarrow 5 \rightarrow 4$ & 50 & 3 & Single \\
\hline 7 & 2 & 6 & $2 \rightarrow 6$ & 31 & 2 & Single \\
\hline 8 & 2 & 8 & $2 \rightarrow 5 \rightarrow 8$ & 33 & 2 & Grouped \\
\hline 9 & 3 & 1 & $3 \rightarrow 2 \rightarrow 1$ & 28 & 2 & Single \\
\hline 10 & 4 & 1 & $4 \rightarrow 1$ & 16 & 1 & Single \\
\hline 11 & 4 & 2 & $4 \rightarrow 2$ & 32 & 2 & Grouped \\
\hline 12 & 4 & 5 & $4 \rightarrow 5$ & 32 & 2 & Single \\
\hline 13 & 4 & 6 & $4 \rightarrow 5 \rightarrow 6$ & 48 & 3 & Grouped \\
\hline 14 & 4 & 7 & $4 \rightarrow 7$ & 48 & 3 & Single \\
\hline 15 & 4 & 8 & $4 \rightarrow 8$ & 22 & 2 & Single \\
\hline 16 & 5 & 1 & $5 \rightarrow 1$ & 11 & 1 & Single \\
\hline 17 & 6 & 2 & $6 \rightarrow 2$ & 32 & 2 & Single \\
\hline 18 & 6 & 4 & $6 \rightarrow 5 \rightarrow 4$ & 35 & 2 & Single \\
\hline 19 & 6 & 5 & $6 \rightarrow 5$ & 19 & 2 & Single \\
\hline 20 & 6 & 8 & $6 \rightarrow 8$ & 31 & 2 & Single \\
\hline 21 & 7 & 4 & $7 \rightarrow 4$ & 23 & 2 & Single \\
\hline 22 & 7 & 8 & $7 \rightarrow 8$ & 27 & 2 & Single \\
\hline 23 & 8 & 2 & $8 \rightarrow 5 \rightarrow 2$ & 63 & 4 & Single \\
\hline 24 & 8 & 4 & $8 \rightarrow 4$ & 18 & 1 & Single \\
\hline 25 & 8 & 6 & $8 \rightarrow 6$ & 48 & 3 & Single \\
\hline 26 & 8 & 7 & $8 \rightarrow 7$ & 23 & 2 & Single \\
\hline
\end{tabular}

the organizational forms and characteristics of the train trip package transport, as well as the existing research results and experiences of passenger train plan. Computational tests show that the proposed model can effectively reduce the cost of transportation. The model can also optimize the operation number of train trip packages in the experiment, indicating that it has better applicability.

An issue of future research is the consideration of more constraints, such as the inconsistent loading cost between single set of trains and group trains and the constraints of facing operation. In further studies, these constraints will be considered in order to get closer to the actual situation.

\section{Conflict of Interests}

The authors declare that there is no conflict of interests regarding the publication of this paper.

\section{Acknowledgments}

This research is supported by Railway Ministry Science and Technology Management Project (2013X014-C), China Railway Corporation Project (2014X010-A), and Fundamental Research Funds for the Central Universities (Beijing Jiaotong University) under Grant no. 2014JBZ008.

\section{References}

[1] A. A. Assad, "Models for rail transportation," Transportation Research Part A: General, vol. 14, no. 3, pp. 205-220, 1980.

[2] A. A. Assad, "Modelling of rail networks: toward a routing/ makeup model," Transportation Research Part B, vol. 14, no. 12, pp. 101-114, 1980.

[3] C. Barnhart, N. Krishnan, D. Kim, and K. Ware, "Network design for express shipment delivery," Computational Optimization and Applications, vol. 21, no. 3, pp. 239-262, 2002.

[4] J. M. Farvolden and W. B. Powell, "Subgradient methods for the service network design problem," Transportation Science, vol. 28, no. 3, pp. 256-272, 1994.

[5] Z. Gao, J. Wu, and H. Sun, "Solution algorithm for the bi-level discrete network design problem," Transportation Research Part B: Methodological, vol. 39, no. 6, pp. 479-495, 2005.

[6] H.-Q. Peng and Y.-J. Zhu, "Intercity train operation schemes based on passenger flow dynamic assignment," Journal of Transportation Systems Engineering and Information Technology, vol. 13, no. 1, pp. 111-117, 2013.

[7] M. H. Keaton, "Designing railroad operating plans: a dual adjustment method for implementing lagrangian relaxation," Transportation Science, vol. 26, no. 4, pp. 263-279, 1992.

[8] M. Yaghini, M. Momeni, and M. Sarmadi, "An improved local branching approach for train formation planning," Applied Mathematical Modelling, vol. 37, no. 4, pp. 2300-2307, 2013. 
[9] K. R. Smilowitz, A. Atamtürk, and C. F. Daganzo, "Deferred item and vehicle routing within integrated networks," Transportation Research Part E: Logistics and Transportation Review, vol. 39, no. 4, pp. 305-323, 2003.

[10] Y. Sun, C. Cao, and C. Wu, "Multi-objective optimization of train routing problem combined with train scheduling on a high-speed railway network," Transportation Research Part C: Emerging Technologies, vol. 44, pp. 1-20, 2014.

[11] T. G. Crainic, "Service network design in freight transportation," European Journal of Operational Research, vol. 122, no. 2, pp. 272-288, 2000.

[12] C. Barnhart, H. Jin, and P. H. Vance, "Railroad blocking: a network design application," Operations Research, vol. 48, no. 4, pp. 603-614, 2000.

[13] Y.-H. Chang, C.-H. Yeh, and C.-C. Shen, "A multiobjective model for passenger train services planning: application to Taiwan's high-speed rail line," Transportation Research Part B: Methodological, vol. 34, no. 2, pp. 91-106, 2000.

[14] T. G. Crainic and J.-M. Rousseau, "Multicommodity, multimode freight transportation: a general modeling and algorithmic framework for the service network design problem," Transportation Research Part B, vol. 20, no. 3, pp. 225-242, 1986.

[15] M. R. Bussieck, P. Kreuzer, and U. T. Zimmermann, "Optimal lines for railway systems," European Journal of Operational Research, vol. 96, no. 1, pp. 54-63, 1997.

[16] B. Yu, H. Zhu, W. Cai, N. Ma, Q. Kuang, and B. Yao, “Twophase optimization approach to transit hub location-the case of Dalian," Journal of Transport Geography, vol. 33, pp. 62-71, 2013.

[17] H. N. Newton, C. Barnhart, and P. H. Vance, "Constructing railroad blocking plans to minimize handling costs," Transportation Science, vol. 32, no. 4, pp. 330-345, 1998.

[18] B. Z. Yao, B. Yu, P. Hu, J. J. Gao, and M. H. Zhang, "An improved particle swarm optimization for carton heterogeneous vehicle routing problem with a collection depot," Annals of Operations Research, 2014.

[19] B. Z. Yao, P. Hu, X. H. Lu, J. J. Gao, and M. H. Zhang, "Transit network design based on travel time reliability;" Transportation Research Part C: Emerging Technologies, vol. 43, pp. 233-248, 2014.

[20] B. Z. Yao, P. Hu, M. H. Zhang, and M. Q. Jin, "A support vector machine with the tabu search algorithm for freeway incident detection," International Journal of Applied Mathematics and Computer Science, vol. 24, no. 2, pp. 397-404, 2014.

[21] B. Yu, N. Ma, W. J. Cai, T. Li, X. T. Yuan, and B. Z. Yao, "Improved ant colony optimisation for the dynamic multi-depot vehicle routing problem," International Journal of Logistics Research and Applications, vol. 16, no. 2, pp. 144-157, 2013.

[22] Y. D. Zhang, S. H. Wang, G. L. Ji, and Z. C. Dong, "Genetic pattern search and its application to brain image classification," Mathematical Problems in Engineering, vol. 2013, Article ID 580876, 8 pages, 2013.

[23] Y. D. Zhang, S. H. Wang, and G. L. Ji, "A rule-based model for bankruptcy prediction based on an improved genetic ant colony algorithm," Mathematical Problems in Engineering, vol. 2013, Article ID 753251, 10 pages, 2013.

[24] B. Yu, Z. Z. Yang, X. S. Sun, B. Yao, Q. Zeng, and E. Jeppesen, "Parallel genetic algorithm in bus route headway optimization," Applied Soft Computing Journal, vol. 11, no. 8, pp. 5081-5091, 2011.
[25] H. Derbel, B. Jarboui, S. Hanafi, and H. Chabchoub, "Genetic algorithm with iterated local search for solving a locationrouting problem," Expert Systems with Applications, vol. 39, no. 3, pp. 2865-2871, 2012. 


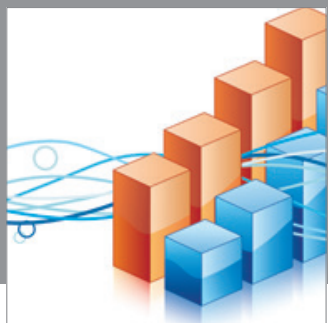

Advances in

Operations Research

mansans

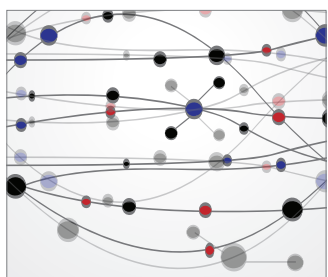

The Scientific World Journal
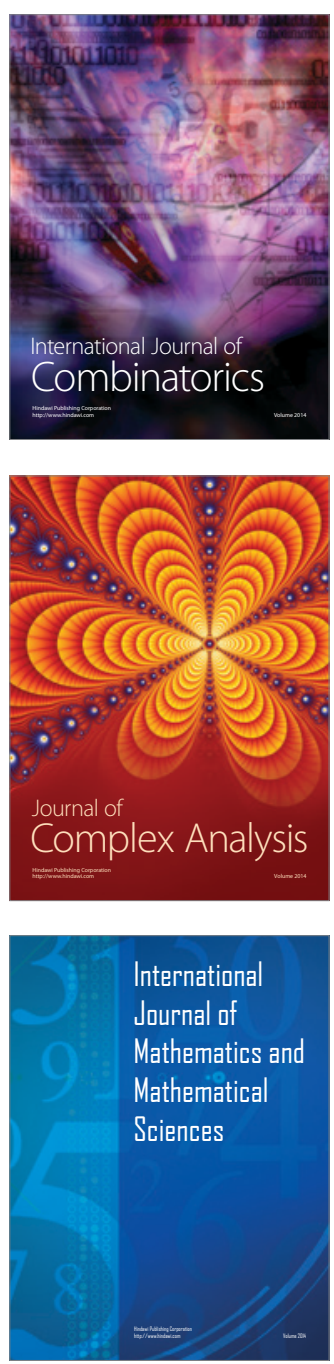
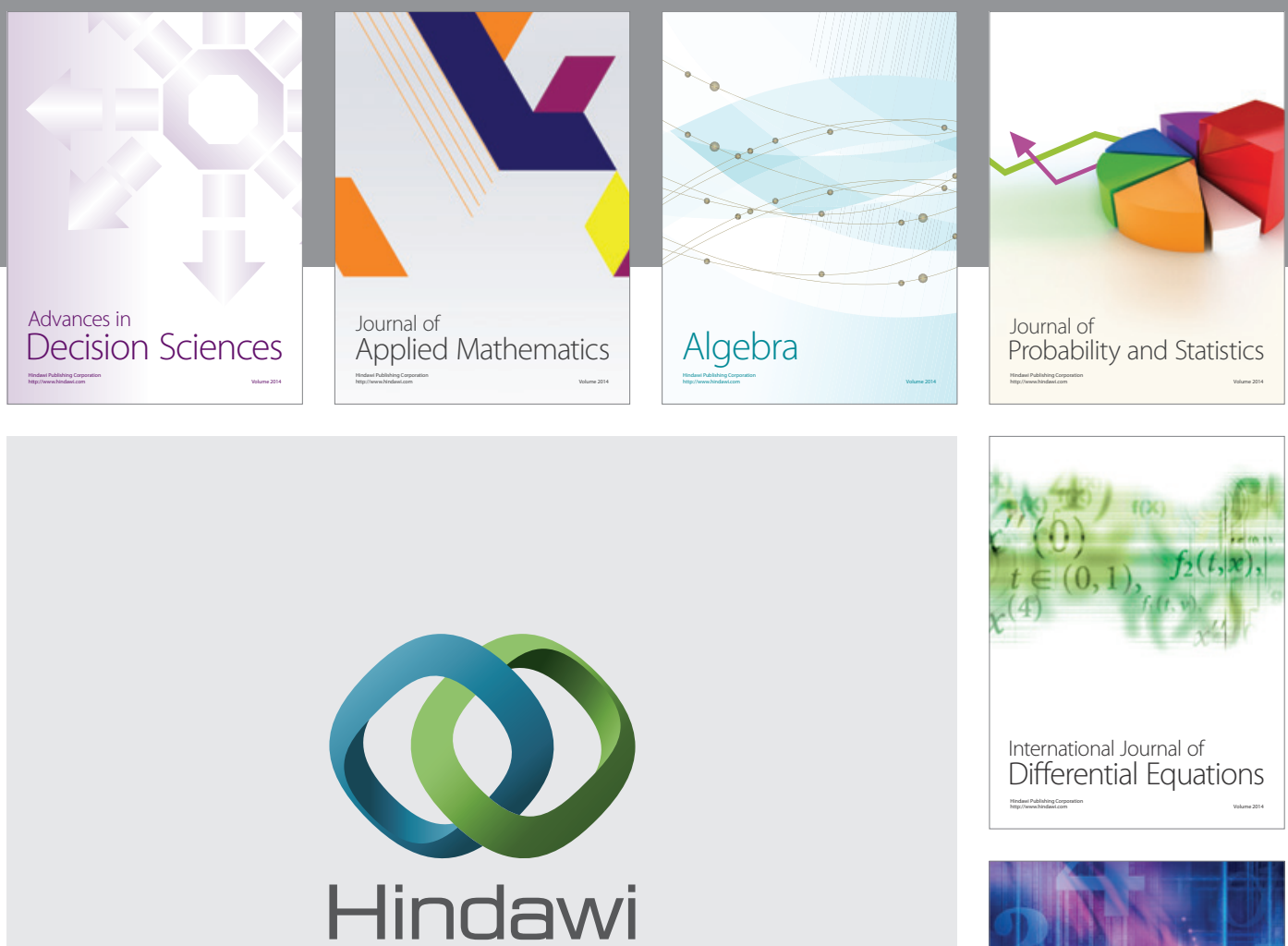

Submit your manuscripts at http://www.hindawi.com
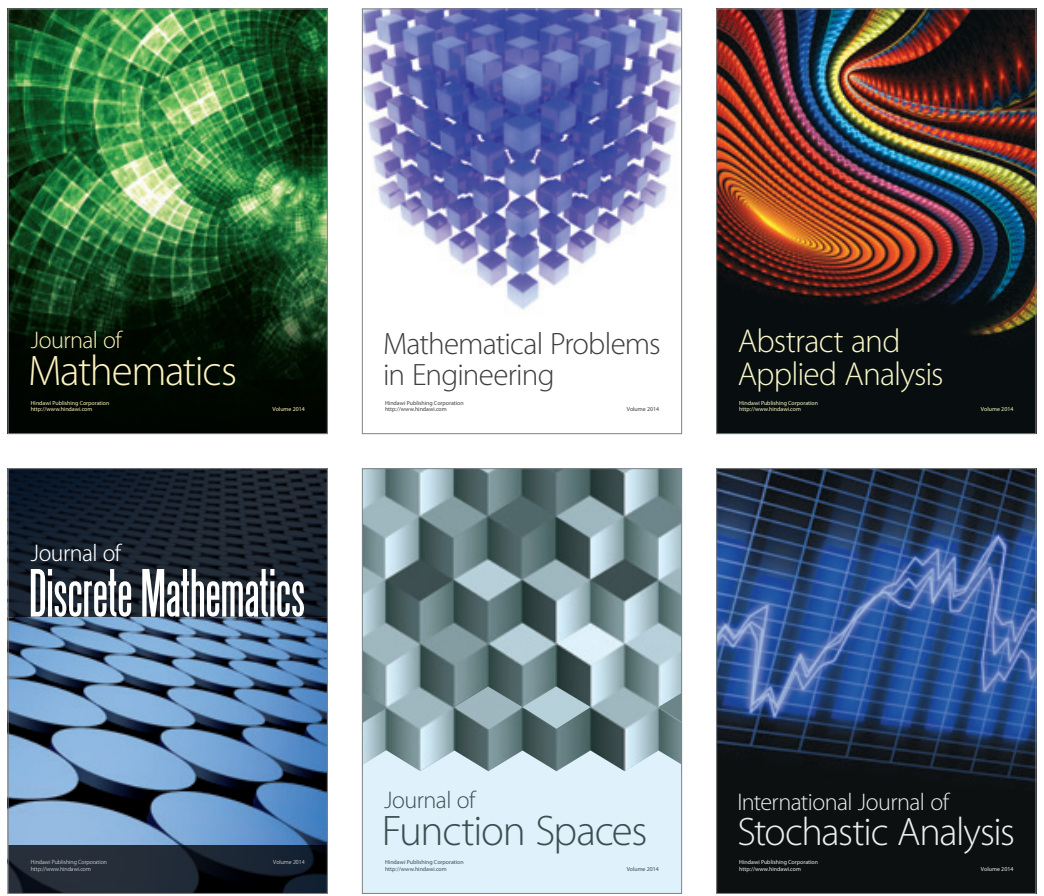

Journal of

Function Spaces

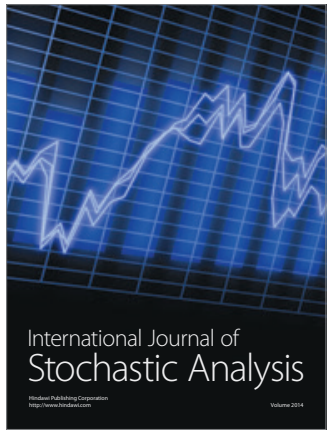

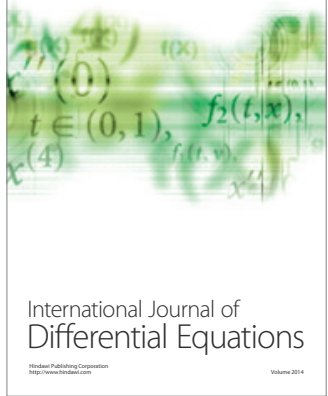
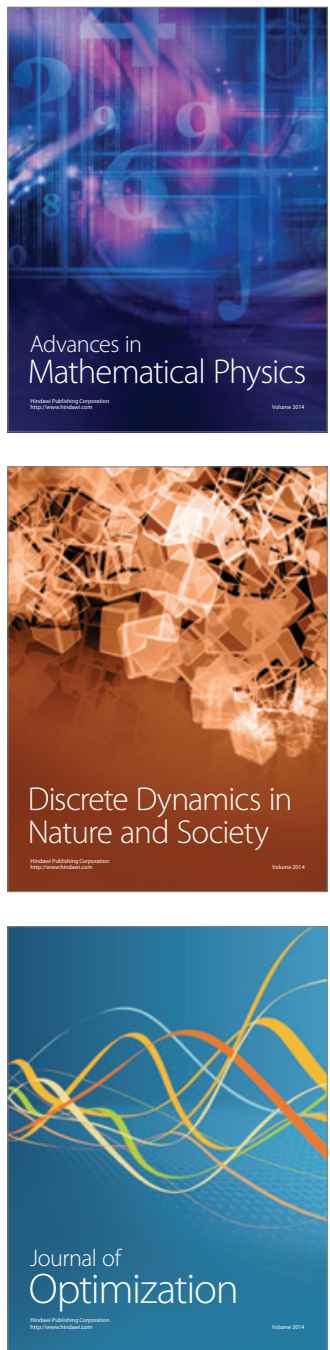